\title{
Effects of Nanoparticle Hydroxyapatite on Growth and Antioxidant System in Pakchoi (Brassica chinensis L.) from Cadmium-Contaminated Soil
}

\author{
Zhangwei Li and Jiaai Huang \\ Department of Chemistry, Hanshan Normal University, Chaozhou 521041, China \\ Correspondence should be addressed to Zhangwei Li; 99094001@163.com
}

Received 12 December 2013; Revised 10 February 2014; Accepted 24 February 2014; Published 23 March 2014

Academic Editor: Arun Kumar

Copyright (C) $2014 \mathrm{Z}$. Li and J. Huang. This is an open access article distributed under the Creative Commons Attribution License, which permits unrestricted use, distribution, and reproduction in any medium, provided the original work is properly cited.

\begin{abstract}
The effects of nanoscale particle hydroxyapatite (nHAP) on biomass, Cd uptake, the level of chlorophyll, vitamin C, malondialdehyde (MDA), and the activities of antioxidant enzymes, including SOD, CAT, and POD in pakchoi in Cd-contaminated soil, were evaluated by conducting pot experiment. Results showed that, by application of the $5 \mathrm{~g} \cdot \mathrm{kg}^{-1}, 10 \mathrm{~g} \cdot \mathrm{kg}^{-1}, 20 \mathrm{~g} \cdot \mathrm{kg}^{-1}$, and $30 \mathrm{~g} \cdot \mathrm{kg}^{-1}$ nHAP in $10 \mathrm{mg} \cdot \mathrm{kg}^{-1} \mathrm{Cd}$-contaminated soil, the biomass of plant increased by $7.97 \%, 13.21 \%, 19.53 \%$, and $20.23 \%$, respectively. In addition, the reduction of $\mathrm{Cd}$ in shoots was $27.12 \%, 44.20 \%, 50.91 \%$, and $62.36 \%$ compared to control samples. It was found that the supplement of the nHAP can increase the level of chlorophyll and vitamin $\mathrm{C}$ and decrease the level of MDA in plant shoots. Furthermore, the increment activities of SOD, CAT, and POD can be observed after addition of nHAP in Cd-contaminated soil. The results confirmed that nHAP can be applied to reduce the plant uptake of $\mathrm{Cd}$ and resist the $\mathrm{Cd}$ stress in the plant in Cd-contaminated soil.
\end{abstract}

\section{Introduction}

Cadmium $(\mathrm{Cd})$ is a toxic element which causes serious pollution in both aquatic and terrestrial environments. The accumulation of Cd in soils and their subsequent transfer through the food chain is extremely hazardous to human health. Moreover, Cd taken in by the plant has been shown to interfere with a number of essential metabolic processes, such as having a major negative influence on water and nutrient uptake, resulting in wilting and necrosis of the leaves $[1,2]$. Furthermore, Cd has been reported to interact with components of the photosynthetic apparatus and to inhibit the electron transport processes, thereby diminishing chlorophyll biosynthesis and photosynthetic carbon assimilation $[3,4]$.

Importantly, $\mathrm{Cd}$ has also been proven to induce oxidative stress by causing an overproduction of reactive oxygen species (ROS) and enhancing the level of lipid peroxidation in plant leaves and roots $[2,5,6]$. The overproduction of ROS induces protein, DNA, and lipid damage. Therefore, it is very important for plant cells to control the overproduction of ROS by coordinating the action of several antioxidant enzymes, such as superoxide dismutase (SOD), peroxidase (POD), and catalase (CAT) [7-9]. These enzymes protect against oxidation in the cell by quenching free radicals. For example, SOD catalyzes the dismutation of $\mathrm{O}_{2}{ }^{--}$to $\mathrm{H}_{2} \mathrm{O}_{2}$ and $\mathrm{O}_{2}$ and plays an important role in removing ROS. Subsequently, the $\mathrm{H}_{2} \mathrm{O}_{2}$ produced by SOD is broken down to $\mathrm{H}_{2} \mathrm{O}$ and $\mathrm{O}_{2}$ by CAT, POD, and the ascorbate-glutathione cycle, another critical defense mechanism against oxidative stress by directly reducing $\mathrm{H}_{2} \mathrm{O}_{2}$, and then the oxidized form of ascorbate is, in turn, reduced by dehydroascorbate reductase using glutathione as a substrate. The oxidized glutathione can then be reduced by glutathione reductase in the presence of NADPH [2], allowing the cells to survive under high ROS levels. The response of antioxidant enzymes to $\mathrm{Cd}$ stress has been found to be different among various species and tissues [10]. In general, the activity of antioxidative enzymes is thought to be inversely proportional with $\mathrm{Cd}$ concentration. However, $\mathrm{Cd}$ has been reported to inactivate 
some antioxidative enzymes, such as SOD [11], likely due to SOD's sensitivity to inhibition by $\mathrm{Cd}$ binding to $-\mathrm{SH}$ groups of the enzyme.

The application of HAP is a cost effective and environmentally friendly technique known to significantly immobilize $\mathrm{Cd}$ in contaminated soil [12]. Moreover, nanoscale particle HAP (nHAP) has been proven to be an extremely effective remediation material in Cd-contaminated soil [13], which has been hypothesized to help plants resist $\mathrm{Cd}$-induced stress. However, few studies have been carried out on the effect of nHAPs on the activity of antioxidant enzymes in the plant following Cd contamination of the soil.

Therefore, the purpose of this study was to evaluate the effect of nHAP on Cd-induced stress in pakchoi (Brassica Chinensis L.), a common leafy vegetable consumed by a large majority of the Chinese population. We chose pakchoi for this experiment because of the general health concern with heavy metal accumulation in leafy vegetables in China. Moreover, we investigated the possible induction of oxidative stress by $\mathrm{Cd}$ and whether or not the alteration of these enzymes involved in the antioxidant defense system includes SOD, POD, and CAT. Finally, we studied content changes of chlorophyll, vitamin $\mathrm{C}$, and malondialdehyde (MDA) and their possible involvement in $\mathrm{Cd}$-induced toxicity.

\section{Materials and Methods}

Experiment soil was collected from a vegetable garden. After being dried and ground to pass a $1 \mathrm{~mm}$ sieve, $1.0 \mathrm{~g}$ of homogenized soil sample was digested with $\mathrm{HNO}_{3}, \mathrm{HClO}_{4}$, and HF. The samples were heated until the color became clear, dissolved with several drops of $1 \% \mathrm{HNO}_{3}$, filtered, diluted to a volume of $50 \mathrm{~mL}$ with distilled water, and analyzed for the total content of $\mathrm{Cd}$ [14]. Soil $\mathrm{pH}$ was measured in $1: 2.5$ soil/water with a combination $\mathrm{pH}$ electrode. Soil organic matter was determined by wet digestion with $\mathrm{K}_{2} \mathrm{Cr}_{2} \mathrm{O}_{7} / \mathrm{H}_{2} \mathrm{SO}_{4}$. Available nitrogen $(\mathrm{N})$, phosphorus $(\mathrm{P})$, and potassium $(\mathrm{K})$ were analyzed according to standard methods recommender by $\mathrm{Lu}$ [15]. Some basic physiochemical properties of the soil and the concentrations of $\mathrm{Cd}$ in this soil were listed in Table 1.

2.1. Treatments. Two-kilogram soil sample was packed into each pot. The $\mathrm{Cd}$ was supplied to soil as solutions of $\mathrm{CdSO}_{4}$. The three treatments were T0 (without $\mathrm{Cd}$ added), $\mathrm{T} 1$ (5 mg. $\mathrm{kg}^{-1} \mathrm{Cd}$ added), and T2 (10 mg. $\mathrm{kg}^{-1} \mathrm{Cd}$ added). Soil amendment used in this experiment was nanometer particle hydroxyapatite (nHAP, bough from Emperor Company, China; particle diameter $<60 \mathrm{~nm}$ ). No Cd was detected in this material. nHAP was applied at five level for T0, T1, and T2 treatment level: $0 \mathrm{~g} \cdot \mathrm{kg}^{-1}, 5 \mathrm{~g} \cdot \mathrm{kg}^{-1}, 10 \mathrm{~g} \cdot \mathrm{kg}^{-1}, 20 \mathrm{~g} \cdot \mathrm{kg}^{-1}$, and $30 \mathrm{~g} \cdot \mathrm{kg}^{-1}$, respectively. There were four replicates in each treatment.

Soil amendments were thoroughly mixed with soil prior to potting; nitrogen ( $4 \mathrm{~g} \cdot \mathrm{pot}^{-1}$ soil as $\mathrm{NH}_{4} \mathrm{NO}_{3}$ ) and potassium ( $4 \mathrm{~g} \cdot \operatorname{pot}^{-1}$ soil as $\mathrm{KCl}$ ) were added in soil as fertilizers. Pots containing $2.0 \mathrm{~kg}$ of soil were used in this experiment. The pots were kept moist for 2 weeks before planting
TABLE 1: Basic properties of the soil.

\begin{tabular}{|c|c|c|c|c|c|}
\hline \multirow{2}{*}{$\mathrm{pH}$} & \multirow{2}{*}{$\begin{array}{l}\text { Organic matter } \\
\qquad\left(\mathrm{g} \cdot \mathrm{kg}^{-1}\right)\end{array}$} & \multicolumn{3}{|c|}{ Available $\left(\mathrm{mg} \cdot \mathrm{kg}^{-1}\right)$} & \multirow{2}{*}{$\begin{array}{c}\text { Total }\left(\mathrm{mg} \cdot \mathrm{kg}^{-1}\right) \\
\text { Cd }\end{array}$} \\
\hline & & $\mathrm{N}$ & $\mathrm{P}$ & K & \\
\hline 6.42 & 17.63 & 98.32 & 17.20 & 74.81 & 0.13 \\
\hline
\end{tabular}

vegetable. 10 seedlings of pakchoi were transplanted into the soil and thinned to four per pot on day 10 and kept in the green house (with natural light) until harvest. Plants were harvested 2 months after emergence.

After harvest, the plants were removed from the soils. After being washed with deionised water, the plants were cut into two parts: shoots and roots. Some fresh leaves were taken for the chlorophyll, MDA, vitamin C, and enzyme assay. The other shoots and roots were put into the oven to dry at $70^{\circ} \mathrm{C}$ until reaching constant weight, passed through $2 \mathrm{~mm}$ sieve for further experiment.

$\mathrm{Cd}$ in plant was extracted by using acid digestion mixture $\left(\mathrm{HNO}_{3}\right.$ and $\left.\mathrm{HClO}_{4}\right)$. The supernatant was obtained from the digested, filtered, reconstituted to the desired volume, and determined by inductively coupled plasma optical emission spectrometry (ICP-OES) for Cd content. Standard reference materials of plant (GSV-4, GBW07605, tea leaves) were used for quality control.

2.2. Enzyme Assay. Enzyme extractions were carried out at $4^{\circ} \mathrm{C}$. The plant leaves were homogenized to powder in liquid nitrogen and extracted in $100 \mathrm{mmol} \cdot \mathrm{L}^{-1}$ potassium phosphate buffer ( $\mathrm{pH} 7.5)$, which contained $1 \%(\mathrm{w} / \mathrm{v})$ insoluble polyvinylpolypyrrolidone (pvpp) and $1 \mathrm{mmol} \cdot \mathrm{L}^{-1}$ EDTA. The homogenate was centrifuged at $25000 \times \mathrm{g}$ for $20 \mathrm{~min}$ and the supernatant was applied for enzyme assay. SOD, POD, and CAT activities were determined by the method of Gajewska et al. [16]. Total SOD activity was determined spectrophotometrically based on pyrogallol autooxidation. The reaction contained 0.1 mM EDTA, 0.055 $\mu \mathrm{M}$ NBT, 1.4\% Triton X-100, $50 \mathrm{mM}$ Tris-cacodylic buffer, $\mathrm{pH}$ 8.2, enzyme extract (about $20 \mu \mathrm{g}$ protein), and $16 \mu \mathrm{M}$ pyrogallol. The reaction system was incubated in $37^{\circ} \mathrm{C}$ for $5 \mathrm{~min}$. The reaction was stopped by addition of $3.5 \mathrm{~mL}$ of mixture including $0.35 \mathrm{M}$ formic buffer, pH 3.5, 0.6\% Triton X-100, and 3.5\% formaldehyde and absorbance was assayed at $540 \mathrm{~nm}$. One unit of SOD activity was expressed as the amount of enzyme that caused inhibition of NBT reduction by $50 \%$. POD activity determinate reaction mixture contained $5.4 \mathrm{mM}$ guaiacol, $15 \mathrm{mM} \mathrm{H}_{2} \mathrm{O}_{2}, 50 \mathrm{mM}$ sodium acetate buffer $\mathrm{pH}$ 5.6, and enzyme extract (about $5 \mu \mathrm{g}$ protein). The increase in absorbance due to the oxidation of guaiacol to tetraguaiacol was assayed at $470 \mathrm{~nm}$. CAT activity determinate reaction mixture consisted of $15 \mathrm{mM}$ $\mathrm{H}_{2} \mathrm{O}_{2}, 50 \mathrm{mM}$ sodium phosphate buffer $\mathrm{pH} 7.0$ and enzyme extract (about $5 \mu \mathrm{g}$ protein). Decomposition of $\mathrm{H}_{2} \mathrm{O}_{2}$ was assayed at $240 \mathrm{~nm}$.

2.3. Determination of Chlorophyll, Vitamin C, and MDA Content. Before extraction, fresh leaf samples were cleaned with deionized water to remove any surface contaminants. The chlorophyll photosynthetic pigments were extracted in $80 \%$ 
TABLE 2: Biomass of pakchoi (Brassica chinensis L.) grown in the uncontaminated soil and contaminated soil with nHAP (total weigh, g/pot, fresh weigh).

\begin{tabular}{lccc}
\hline $\begin{array}{l}\text { nHAP treatment level } \\
\left(\mathrm{mg} \cdot \mathrm{kg}^{-1}\right)\end{array}$ & $\begin{array}{c}\text { Cd treatment level (T0) } \\
0 \mathrm{mg} \cdot \mathrm{kg}^{-1}\end{array}$ & $\begin{array}{c}\text { Cd treatment level (T1) } \\
5 \mathrm{mg} \cdot \mathrm{kg}^{-1}\end{array}$ & $\begin{array}{c}\text { Cd treatment level (T2) } \\
10 \mathrm{mg} \cdot \mathrm{kg}^{-1}\end{array}$ \\
\hline 0.0 & $71.22 \pm 4.08^{\mathrm{ab}}$ & $59.55 \pm 4.49^{\mathrm{b}}$ & $50.80 \pm 5.30^{\mathrm{b}}$ \\
5.0 & $72.36 \pm 2.47^{\mathrm{a}}$ & $62.19 \pm 3.91^{\mathrm{ab}}$ & $54.85 \pm 1.06^{\mathrm{ab}}$ \\
10.0 & $67.36 \pm 5.71^{\mathrm{ab}}$ & $65.05 \pm 2.77^{\mathrm{a}}$ & $57.51 \pm 3.83^{\mathrm{ab}}$ \\
20.0 & $66.54 \pm 1.63^{\mathrm{ab}}$ & $65.27 \pm 5.87^{\mathrm{a}}$ & $60.73 \pm 4.48^{\mathrm{a}}$ \\
30.0 & $64.33 \pm 6.53^{\mathrm{b}}$ & $62.49 \pm 2.28^{\mathrm{ab}}$ & $61.08 \pm 5.79^{\mathrm{a}}$ \\
\hline
\end{tabular}

Mean values denoted by the same letter in a column do not differ significantly according to the Duncan test.

TABLE 3: Concentration of Cd in pakchoi (Brassica chinensis L.) grown in Cd contaminated soil in pot culture receiving nHAP amendments (mg. $\mathrm{kg}^{-1}$, dry weigh).

\begin{tabular}{|c|c|c|c|c|c|c|}
\hline \multirow{2}{*}{$\begin{array}{l}\text { nHAP treatment level } \\
\left(\mathrm{mg} \cdot \mathrm{kg}^{-1}\right)\end{array}$} & \multicolumn{2}{|c|}{$\begin{array}{c}\text { Cd treatment level (T0) } \\
0 \mathrm{mg} \cdot \mathrm{kg}^{-1}\end{array}$} & \multicolumn{2}{|c|}{$\begin{array}{l}\text { Cd treatment level (T1) } \\
5 \mathrm{mg} \cdot \mathrm{kg}^{-1}\end{array}$} & \multicolumn{2}{|c|}{$\begin{array}{l}\text { Cd treatment level (T2) } \\
10 \mathrm{mg} \cdot \mathrm{kg}^{-1}\end{array}$} \\
\hline & Shoot & Root & Shoot & Root & Shoot & Root \\
\hline 0.0 & $0.33 \pm 0.02^{\mathrm{a}}$ & $0.58 \pm 0.03^{\mathrm{a}}$ & $18.35 \pm 0.58^{\mathrm{a}}$ & $24.87 \pm 1.06^{\mathrm{a}}$ & $30.45 \pm 1.71^{\mathrm{a}}$ & $41.96 \pm 2.85^{\mathrm{a}}$ \\
\hline 5.0 & $0.21 \pm 0.01^{b}$ & $0.45 \pm 0.01^{\mathrm{b}}$ & $17.08 \pm 0.73^{b}$ & $23.80 \pm 2.44^{\mathrm{a}}$ & $22.19 \pm 1.38^{\mathrm{b}}$ & $31.26 \pm 2.46^{\mathrm{b}}$ \\
\hline 10.0 & $0.24 \pm 0.02^{\mathrm{b}}$ & $0.42 \pm 0.02^{\mathrm{b}}$ & $14.97 \pm 0.44^{\mathrm{c}}$ & $19.44 \pm 1.63^{\mathrm{b}}$ & $16.99 \pm 0.89^{c}$ & $19.58 \pm 0.97^{\mathrm{c}}$ \\
\hline 20.0 & $0.25 \pm 0.04^{\mathrm{b}}$ & $0.41 \pm 0.02^{b}$ & $7.55 \pm 0.36^{\mathrm{d}}$ & $14.39 \pm 0.48^{\mathrm{c}}$ & $14.93 \pm 0.63^{\mathrm{d}}$ & $17.35 \pm 1.22^{\mathrm{cd}}$ \\
\hline 30.0 & $0.19 \pm 0.03^{c}$ & $0.44 \pm 0.03^{\mathrm{b}}$ & $6.12 \pm 0.51^{\mathrm{e}}$ & $10.86 \pm 0.57^{\mathrm{d}}$ & $11.46 \pm 0.69^{\mathrm{e}}$ & $14.52 \pm 0.73^{\mathrm{d}}$ \\
\hline
\end{tabular}

Mean values denoted by the same letter in a column do not differ significantly according to the Duncan test.

acetone at $4^{\circ} \mathrm{C}$. The resulting suspension was centrifuged for $5 \mathrm{~min}$ at $3000 \times \mathrm{g}$; then the absorbance of the supernatant was assayed at 460, 645, and $665 \mathrm{~nm}$ with an UV spectrometer [17]. The MDA of plant leaves was determined according to Lin et al. [18]. MDA was assayed by measuring the concentration of thiobarbituric acid-reacting substances. The leaves were homogenized in 5\% (w/v) trichloroacetic acid (TCA). After centrifugation, a sample of the supernatant was addition of $20 \%$ TCA consisting of $0.5 \%(\mathrm{w} / \mathrm{v})$ thiobarbituric acid. The mixture was incubated at $95^{\circ} \mathrm{C}$ for $30 \mathrm{~min}$. Then the absorbance of the supernatant was assayed at 532,600, and $450 \mathrm{~nm}$ with an UV spectrometer. Vitamin C was determined according to the method of Lu [15]. The leaves were homogenized in $2 \%$ oxalic acid. After centrifugation, a sample of the supernatant was addition of $1 \%$ oxalic acid, a drop of thiourea, and 2,4-dinitrophenylhydrazine. The mixture was incubated at $37^{\circ} \mathrm{C}$ for 3 hours. After addition of $85 \% \mathrm{H}_{2} \mathrm{SO}_{4} 2 \mathrm{~mL}$, the absorbance of the supernatant was assayed at $540 \mathrm{~nm}$ with an UV spectrometer.

2.4. Statistical Analysis. The means and standard deviations (SD) were calculated by Excel 2003. Statistical analysis including the analysis of variance was conducted using SPSS version 17.0 software (SPSS Inc., USA) and differences $(P<0.05)$ between means were determined using the Duncan test. The figures were plotted by origin 7.5 .

\section{Results and Discussions}

3.1. Effect of $n$ HAP on the Growth and Uptake of Cd by Pakchoi. The biomass of the pakchoi was significantly decreased by $\mathrm{Cd}$ application at $\mathrm{T} 1$ and $\mathrm{T} 2$ treatment level compared to the T0 treatment level (Table 2). As Table 2 showed, the reduction of biomass of pakchoi was $16.4 \%$ and $28.7 \%$ at $\mathrm{T} 1$ and $\mathrm{T} 2$ treatment level without adding of nHAP which compared to that of the control. However, it was reported [19] that excessive $\mathrm{Cd}$ contents in soil can restrain the development of root system of plant, inhibit photosynthesis, and even reduce the biomass of plant. This result corresponded with the opinion. The biomass of the pakchoi increased with the increasing of the nHAP addition level except applying for $30 \mathrm{~g} \cdot \mathrm{kg}^{-1}$ in $\mathrm{T} 1$ treatment level. As the result showed, by supplement of $5,10,20$, and $30 \mathrm{~g} \cdot \mathrm{kg}^{-1} \mathrm{nHAP}$, the increment of pakchoi biomass was $4.4 \%, 9.2 \%, 9.6 \%$, and $4.9 \%$ in $\mathrm{T} 1$ treatment level and $8.0 \%, 13.2 \%, 19.5$, and $20.2 \%$ in $\mathrm{T} 2$ treatment level as compared to the unamendment treatment in $\mathrm{T} 1$ and $\mathrm{T} 2$ level. It can be observed that, after adding the level of $20 \mathrm{~g} \cdot \mathrm{kg}^{-1}$ nHAP to T1 and $30 \mathrm{~g} \cdot \mathrm{kg}^{-1}$ nHAP to T2 Cd treatment level, the biomass of plant reached the top value in each $\mathrm{Cd}$-contaminated level. This result may be due to the fact that the nHAP can release the toxic effect on pakchoi caused by $\mathrm{Cd}$ treatment, resulting in the increment of the biomass of pakchoi. Another reason may lie in the fact that more phosphate nutrition supplement after phosphate amendments addition can promote the growth of the pakchoi $[12]$.

The application of nHAP significantly reduced the concentration of $\mathrm{Cd}$ in the shoots and roots of the pakchoi grown in the Cd-contaminated soil (Table 3 ). It was shown that, after the addition of the $5,10,20$, and $30 \mathrm{~g} \cdot \mathrm{kg}^{-1} \mathrm{nHAP}$, the reduction of concentrations of $\mathrm{Cd}$ in the pakchoi shoots was $6.9 \%, 18.4 \%, 58.9 \%$, and $66.6 \%$ in $\mathrm{T} 1$ treatment level 
and $27.1 \%, 44.2 \%, 51.0 \%$, and $62.4 \%$ in $\mathrm{T} 2$ treatment level as compared to the unamendment treatment in $\mathrm{T} 1$ and $\mathrm{T} 2$ level. The reduction of concentrations of $\mathrm{Cd}$ in the pakchoi roots was $4.3 \%, 21.8 \%, 42.1 \%$, and $56.3 \%$ in $\mathrm{T} 1$ treatment level and $25.5 \%, 53.3 \%, 58.7 \%$, and $65.4 \%$ in T2 treatment level as compared to the unamendment treatment in T1 and T2 level. It can be found that the application of $30 \mathrm{~g} \cdot \mathrm{kg}^{-1} \mathrm{nHAP}$ has the best effect on reducing $\mathrm{Pb}$ content in pakchoi shoots and roots in both $\mathrm{T} 1$ and $\mathrm{T} 2$ treatment level.

In this study, it can be found that, while plant exposure to high concentration of $\mathrm{Cd}$ treatment level, some toxicity symptoms like chlorosis and growth reduction were observed. This toxic effect is attributed to the over accumulation of $\mathrm{Cd}$ in leaves and roots. Studies conducted on various plant species have confirmed that $\mathrm{Cd}$ can interfere with many metabolic processes. It blocked down the water and nutrient uptake, resulting in visible symptoms of injury in plants such as chlorosis and necrosis of leaves, and inhibited the growth of roots [2]. However, plant growth was promoted by the supplement of nHAP to the Cd-contaminated soil. This result may be due to the fact that the $\mathrm{nHAP}$ can alleviate the toxic effect on plant caused by Cd treatment, resulting in the increment of the biomass of plant.

3.2. Effect of nHAP on the Content of Chlorophyll, MDA, and Vitamin C in Pakchoi Leaves. Chlorophyll content in the vegetable shoots is an important index indicating the effectiveness of the heavy metal in the plant. In this study, the content of chlorophyll in pakchoi leave decreased with increasing concentrations of $\mathrm{Cd}$ in soil (Figure 1). As compared to the control, the content of chlorophyll decreased by $27.19 \%$ in $\mathrm{T} 1$ treatment and $32.28 \%$ in the T2 treatment. Alternatively, the supplementation of nHAP caused the content of chlorophyll to increase. Chlorophyll levels reached their maximum value both in the T1 and T2 treatment after application of $20 \mathrm{~g} \cdot \mathrm{kg}^{-1}$ nHAP, increasing by $29.99 \%$ and $31.30 \%$ which compared to the T1 and T2 treatment without adding nHAP. Results conclusively showed that the application of nHAP increased the content of chlorophyll in pakchoi under Cd stress.

Figure 1 showed that Cd toxicity increased the total amount of malonaldehyde (MDA) in pakchoi leaves. There was an increase in MDA by $54.82 \%$ and $144.23 \%$ in the T1 and T2 levels, respectively, as compared to the control. Supplementation of a high concentration of nHAP $\left(30 \mathrm{~g} \cdot \mathrm{kg}^{-1}\right)$ caused a subsequent decrease in MDA levels, reducing the content of MDA in pakchoi leave by $33.23 \%$ and $53.00 \%$ in $\mathrm{T} 1$ and $\mathrm{T} 2$ treatment, respectively, as compared to that of the control. This result confirmed that nHAP reduced Cdinduced plant and improved the physiological function in plant.

Increased production of ROS results in the damage biomembrane proteins and phospholipids, leading to membrane destabilization and destructurization $[5,6]$. In this experiment, we hypothesized that $\mathrm{Cd}$ may be involved in lipid peroxidation and membrane damage, based on an observed increase in the MDA content in the plant leaves. The addition of nHAP to Cd-treated soil caused a significant decrease in the MDA content, indicating that nHAP supplementation inhibits ROS.
Furthermore, we found that Cd caused a marked decrease in the total content of chlorophyll. It has been suggested that a reduction in chlorophyll was responsible for the inhibition of photosynthesis and growth via Cd contamination [20]. On one hand, Cd may be interfering with enzymes involved in chlorophyll biosynthesis, such as aminolevulinic acid dehydratase and protochlorophyllide reductase, thus leading to reduction of chlorophyll content. On the other hand, decreases in chlorophyll may be due to oxidation stress caused by $\mathrm{Cd}[2,4,21]$. One way or the other, nHAP protected and restored chlorophyll levels, indicating that the supplementation of nHAP probably maintains chlorophyll synthesis by blocking the Cd toxicity effect on photosynthetic pigments [2], resulting in less damage to the chlorophyll and relieving oxidation stress.

We hypothesize that the high concentration of MDA following Cd-induced stress in the plant was likely the result of an increase in the levels of oxygen free radical. As such, we wanted to look at the role of vitamin C in Cd-induced stress due to its critical action in clearing free radicals from the plant tissue. As shown in Figure 1, Cd treatment led to a significant decrease in vitamin $\mathrm{C}$ content within the pakchoi leaves. However, when being under T1 and T2 treatment levels, the content of vitamin C was significantly decreased (21.88\% and $38.86 \%$ ), as compared to the control. Moreover, the amount of vitamin $\mathrm{C}$ increased with increasing nHAP concentration. The content of vitamin $\mathrm{C}$ in pakchoi reached its maximum value of $13.95 \mathrm{mg} / 100 \mathrm{~g}$ following $20 \mathrm{~g} \cdot \mathrm{kg}^{-1}$ of $\mathrm{nHAP}$ in T1 treatment level, increasing by $48.26 \%$, as compared with plant material under T1-contaminated conditions without any amendment application. Furthermore, nHAP added to $\mathrm{T} 2$ polluted soil also increased vitamin $\mathrm{C}$ content, reaching its maximum value of $13.60 \mathrm{mg} / \mathrm{kg}$ following the supplementation of $30 \mathrm{~g} \cdot \mathrm{kg}^{-1}$ nHAP to the soil, a value of $40.69 \%$ greater T2 treatment controls. These results suggested that the addition of nHAP protected against $\mathrm{Cd}$-induced stress by inhibiting free radicals through a vitamin- $\mathrm{C}$ mediated effect.

\subsection{Effect of nHAP on the Antioxidant Enzymes Activity in} Pakchoi Leaves. SOD activity shown significantly decreased in $\mathrm{T} 1$ and $\mathrm{T} 2$ treatment plant compared to the control (Figure 2). The application of nHAP ( 5 to $30 \mathrm{~g} \cdot \mathrm{kg}^{-1}$ ) to the test soil with Cd led to an increment of SOD activity, indicating that the supplement of nHAP increased the activity of SOD in pakchoi leaves. $\mathrm{T} 1$ and $\mathrm{T} 2$ treatment caused an increase in POD activity up to $26.26 \%$ and $34.25 \%$ compared to the control. The application of nHAP to Cd treatment greatly enhanced the POD activity. When nHAP was supplied to a high level of $20 \mathrm{~g} \cdot \mathrm{kg}^{-1}$ in $\mathrm{T} 1$ treatment and $30 \mathrm{~g} \cdot \mathrm{kg}^{-1}$ in T2 treatment, there was an enhancement of the POD activity by $13.74 \%$ and $17.53 \%$ compared to pakchoi treated with Cd alone. Similar to POD, the CAT activity induced an increment by $10.13 \%$ and $37.16 \%$ in $\mathrm{Cd}$ treated vegetable compared to control. Supplementation of nHAP at the concentration of $30 \mathrm{~g} \cdot \mathrm{kg}^{-1}$ in both T1 and T2 led to a maximum enhancement in CAT activity, which was increased by about $50.80 \%$ and $38.83 \%$ compared to $\mathrm{Cd}$ treatment alone, indicating that applying with nHAP can improve the functioning of CAT. 


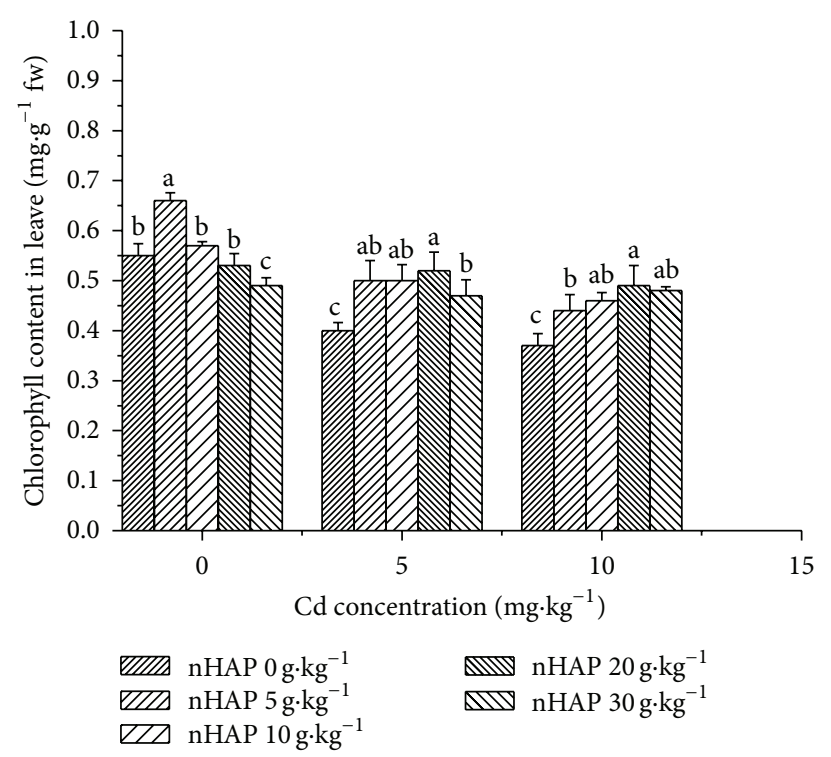

(a)

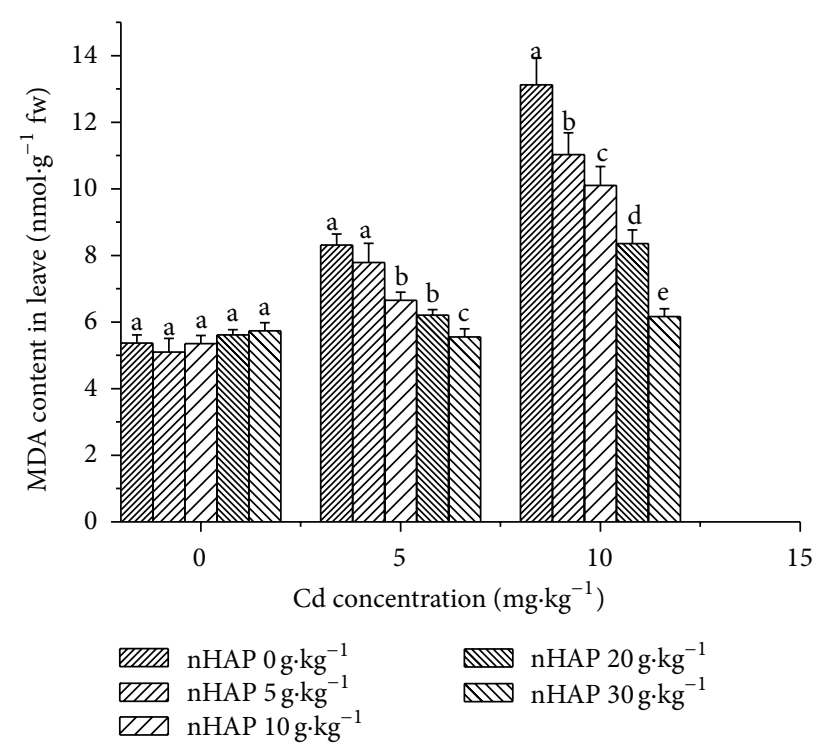

(b)

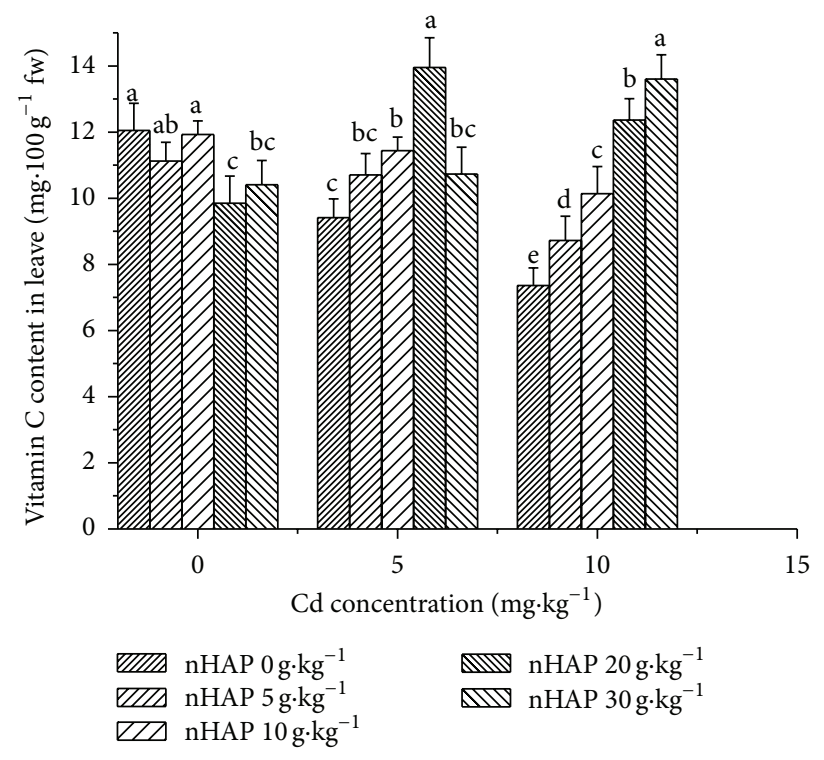

(c)

Figure 1: The content of chlorophyll, MDA, and vitamin $\mathrm{C}$ in plant leaves after different level of nHAP treatment (fresh weigh). Among the same Cd concentration treatments, bars with same letter are not significantly different.

Cd has been proven to induce the overproduction of ROS, leading to increased lipid peroxidation levels and the broken down chlorophyll. In order to eliminate the overproduction of ROS, plants self-activate antioxidant enzymes play a key role in directly quenching free radicals. SOD is one of these antioxidant enzymes, diminishing ROS by catalyzing the dismutation of $\mathrm{O}_{2}{ }^{--}$to $\mathrm{H}_{2} \mathrm{O}_{2}$ and $\mathrm{O}_{2}$ [7]. We found that $\mathrm{Cd}$ inhibits the activity of SOD, likely due to the fact that $\mathrm{Cd}$ competes with $\mathrm{Zn}$ for binding to -SH groups of SOD [2], thus resulting in a decrease in the activity of the enzyme. The application of nHAP to the Cd-contaminated soil enhanced SOD activity in the leaves of the plants. We hypothesize that the supplementation of nHAP diminishes the transfer of $\mathrm{Cd}$ into plant cell by combining with it. As a result, there is less binding of $\mathrm{Cd}$ to SOD, therefore leading to an enhancement of the enzyme activity.

Moreover, $\mathrm{H}_{2} \mathrm{O}_{2}$ produced by SOD is broken down to $\mathrm{H}_{2} \mathrm{O}$ and $\mathrm{O}_{2}$ by CAT. In the current study the activity of both CAT and POD in the leaves was increased by the supplementation of $\mathrm{Cd}$, an effect further enhanced by the application of nHAP to the soil. This result is likely due to the fact that when SOD activity is induced more $\mathrm{H}_{2} \mathrm{O}_{2}$ is produced and accumulated. In order to prevent the $\mathrm{H}_{2} \mathrm{O}_{2}$ from damaging lipids and chlorophyll the other antioxidant enzymes, CAT and POD, need to be overexpressed to break down this accumulation of $\mathrm{H}_{2} \mathrm{O}_{2}[2,21,22]$. Thus, the 


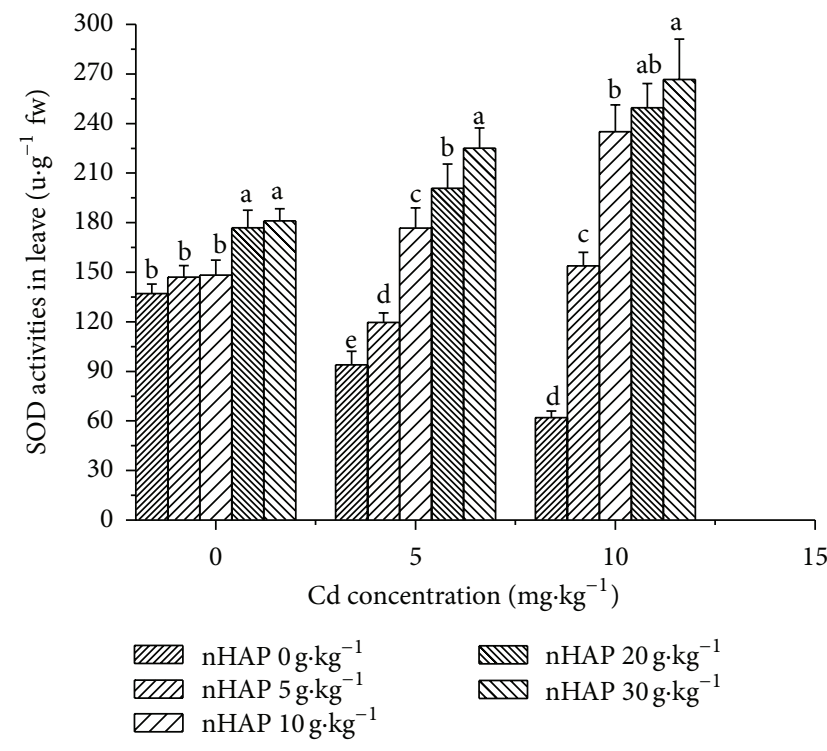

(a)
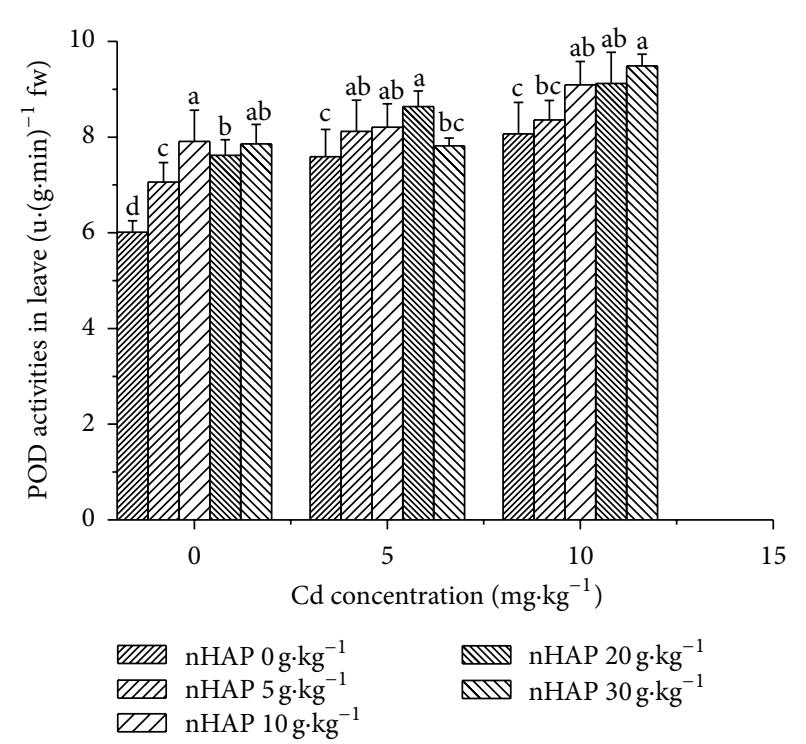

(b)

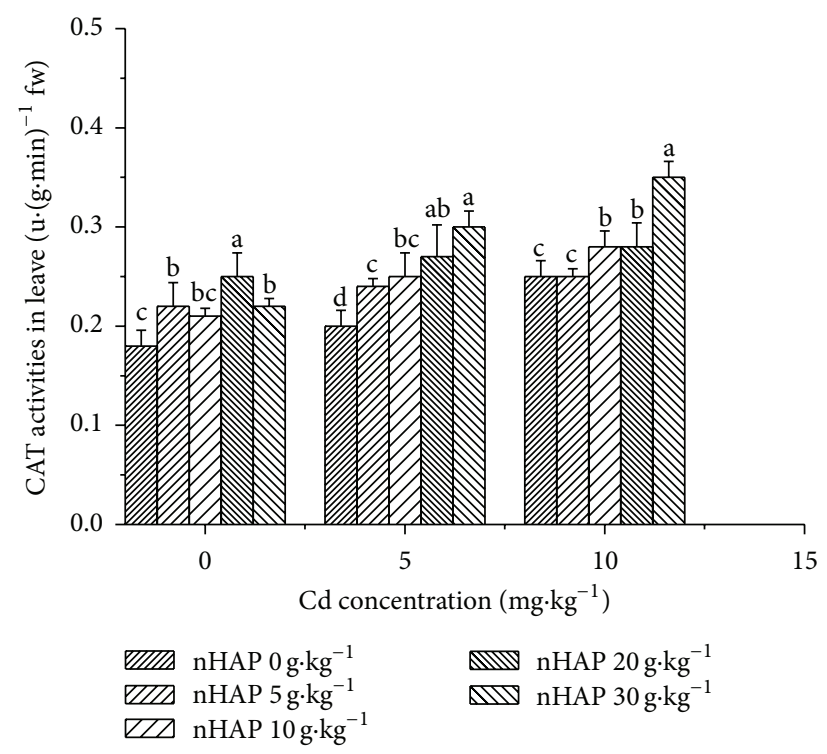

(c)

Figure 2: The content of SOD, POD, and CAT in plant leaves after different level of nHAP treatment (fresh weigh). Among the same Cd concentration treatments, bars with same letter are not significantly different.

addition of nHAP decreased the uptake of Cd, leading to an enhanced level of antioxidant enzymes and more efficient ROS scavenging activity within the cells of the plant.

Nanotechnology is an advanced modern approach widely used throughout the world. As it can offer new types of materials which provide the unique and important solutions to the limitations of other conventional materials, many researchers were focus on it [23-25]. Nanomaterials which have nanoscale dimensions range from 1 to $100 \mathrm{~nm}$ and often exhibit significantly changed physical, chemical, and biological properties because of their structure and larger specific surface area [23-25]. Nanoscale particle HAP has proven to have significant effect on immobilization of heavy metal in water and soil [13]. However, few studies were carried out on the application of nHAP to the plant when facing the oxidative stress induced by the presence of $\mathrm{Cd}$ in contaminated soil. In this study, we confirmed that nHAP directly activities antioxidant enzymes, such as SOD, CAT, and POD in the presence of $\mathrm{Cd}$ contamination. Moreover, nHAP inhibited the uptake of $\mathrm{Cd}$ and blocked Cd-induced increases in MDA. These results suggest that applying nHAP in Cd-contaminated soil is an available approach not only 
for increasing vegetable production, but also for reducing $\mathrm{Cd}$ uptake and improving the quality of the plant for human consumption.

\section{Conclusions}

The results verified the inference that the application of nHAP can increase the level of chlorophyll and vitamin $C$ and decrease the content of MDA in plant shoots. In addition, the activities of antioxidant enzymes like SOD, CAT, and POD can be enhanced by the input of nHAP on Cd-contaminated soil. These results confirmed that the Cd bioavailability can be reduced and the resistance to $\mathrm{Cd}$ stress can be enhanced in Cd-contaminated soil by nHAP.

\section{Conflict of Interests}

The authors declare that there is no conflict of interests regarding the publication of this paper.

\section{Acknowledgment}

This work was supported by the National Spark Program of China (no. 2012GA780051).

\section{References}

[1] M. Li, L. J. Zhang, L. Tao, and W. Li, "Ecophysiological responses of Jussiaea rapens to cadmium exposure," Aquatic Botany, vol. 88, no. 4, pp. 347-352, 2008.

[2] J. Cherif, C. Mediouni, W. B. Ammar, and F. Jemal, "Interactions of zinc and cadmium toxicity in their effects on growth and in antioxidative systems in tomato plants (Solarium lycopersicum)," Journal of Environmental Sciences, vol. 23, no. 5, pp. 837-844, 2011.

[3] X. Li, M. X. Zhao, L. P. Guo, and L. Q. Huang, "Effect of cadmium on photosynthetic pigments, lipid peroxidation, antioxidants, and artemisinin in hydroponically grown Artemisis annua," Journal of Environmental Sciences, vol. 24, no. 8, pp. 1511-1518, 2012.

[4] W. Maksymiec, M. Wójcik, and Z. Krupa, "Variation in oxidative stress and photochemical activity in Arabidopsis thaliana leaves subjected to cadmium and excess copper in the presence or absence of jasmonate and ascorbate," Chemosphere, vol. 66, no. 3, pp. 421-427, 2007.

[5] I. Lefèvre, G. Marchal, M. E. Ghanem, E. Correal, and S. Lutts, "Cadmium has contrasting effects on polyethylene glycolsensitive and resistant cell lines in the Mediterranean halophyte species Atriplex halimus L.," Journal of Plant Physiology, vol. 167, no. 5, pp. 365-374, 2010.

[6] D. K. Gupta, F. T. Nicoloso, M. R. C. Schetinger et al., "Antioxidant defense mechanism in hydroponically grown Zea mays seedlings under moderate lead stress," Journal of Hazardous Materials, vol. 172, no. 1, pp. 479-484, 2009.

[7] N. Dinakar, P. C. Nagajyothi, S. Suresh, Y. Udaykiran, and T. Damodharam, "Phytotoxicity of cadmium on protein, proline and antioxidant enzyme activities in growing Arachis hypogaea L. seedlings," Journal of Environmental Sciences, vol. 20, no. 2, pp. 199-206, 2008.

[8] C. H. Foyer and G. Noctor, "Redox sensing and signalling associated with reactive oxygen in chloroplasts, peroxisomes and mitochondria," Physiologia Plantarum, vol. 119, no. 3, pp. 355-364, 2003.

[9] T. Gichner, Z. Patková, J. Száková, and K. Demnerová, “Toxicity and DNA damage in tobacco and potato plants growing on soil polluted with heavy metals," Ecotoxicology and Environmental Safety, vol. 65, no. 3, pp. 420-426, 2006.

[10] M. J. Hassan, G. S. Shao, and G. P. Zhang, "Influence of cadmium toxicity on growth and antioxidant enzyme activity in rice cultivars with different grain cadmium accumulation," Journal of Plant Nutrition, vol. 28, no. 7, pp. 1259-1270, 2005.

[11] P. Aravind and M. N. V. Prasad, "Zinc alleviates cadmiuminduced oxidative stress in Ceratophyllum demersum L.: a free floating freshwater macrophyte," Plant Physiology and Biochemistry, vol. 41, no. 4, pp. 391-397, 2003.

[12] S. Chen, M. Xu, Y. Ma, and J. Yang, "Evaluation of different phosphate amendments on availability of metals in contaminated soil," Ecotoxicology and Environmental Safety, vol. 67, no. 2, pp. 278-285, 2007.

[13] M. Wang, L. Chen, S. B. Chen, and Y. B. Ma, "Alleviation of cadmium-induced root growth inhibition in crop seedlings by nanoparticles," Ecotoxicology and Environmental Safety, vol. 79, pp. 48-54, 2012.

[14] S. B. Chen, Y. G. Zhu, Y. B. Ma, and G. McKay, "Effect of bone char application on $\mathrm{Pb}$ bioavailability in a $\mathrm{Pb}$-contaminated soil," Environmental Pollution, vol. 139, no. 3, pp. 433-439, 2006.

[15] R. K. Lu, Analytical Methods for Soils and Agricultural Chemistry, China Agricultural Science and Technology Press, Beijing, China, 1999.

[16] E. Gajewska, M. Skłodowska, M. Słaba, and J. Mazur, "Effect of nickel on antioxidative enzyme activities, proline and chlorophyll contents in wheat shoots," Biologia Plantarum, vol. 50, no. 4, pp. 653-659, 2006.

[17] H. K. Lichtenthaler, "[34] Chlorophylls and carotenoids: pigments of photosynthetic biomembranes," Methods in Enzymology, vol. 148, pp. 350-382, 1987.

[18] W. J. Lin, T. F. Xiao, Y. Y. Wu, Z. q. Ao, and Z. P. Ning, "Hyperaccumulation of zinc by Corydalis davidii in Zn-polluted soils," Chemosphere, vol. 86, no. 8, pp. 837-842, 2012.

[19] P. Li, X. X. Wang, T. L. Zhang, D. Zhou, and Y. He, "Effects of several amendments on rice growth and uptake of copper and cadmium from a contaminated soil," Journal of Environmental Sciences, vol. 20, no. 4, pp. 449-455, 2008.

[20] B. H. Liao, H. Y. Liu, S. Q. Lu, K. F. Wang, A. Probst, and J. L. Probst, "Combined toxic effects of cadmium and acid rain on Vicia faba L.," Bulletin of Environmental Contamination and Toxicology, vol. 71, no. 5, pp. 998-1004, 2003.

[21] N. V. Laspina, M. D. Groppa, M. L. Tomaro, and M. P. Benavides, "Nitric oxide protects sunflower leaves against Cd-induced oxidative stress," Plant Science, vol. 169, no. 2, pp. 323-330, 2005.

[22] M. Drz̧kiewicz, E. Skórzyńska-Polit, and Z. Krupa, "Response of the ascorbate-glutathione cycle to excess copper in Arabidopsis thaliana (L.)," Plant Science, vol. 164, no. 2, pp. 195-202, 2003.

[23] R. Q. Liu and R. Lai, "Nanoenhanced materials for reclamation of mine lands and other degraded soils: a review," Journal of Nanotechnology, vol. 2012, Article ID 461468, 18 pages, 2012.

[24] Z. Z. Zhang, M. Y. Li, W. Chen, S. Z. Zhu, N. Liu, and L. Y. Zhu, "Immobilization of lead and cadmium from aqueous solution and contaminated sediment using nano-hydroxyapatite," Environmental Pollution, vol. 158, no. 2, pp. 514-519, 2010.

[25] H. B. Cui, J. Zhou, Q. G. Zhao et al., "Fractions of Cu, Cd and enzyme activities in a contaminated soil as affected by applications of micro- and nanohydroxyapatite," Journal of Soils and Sediments, vol. 13, no. 4, pp. 742-752, 2013. 

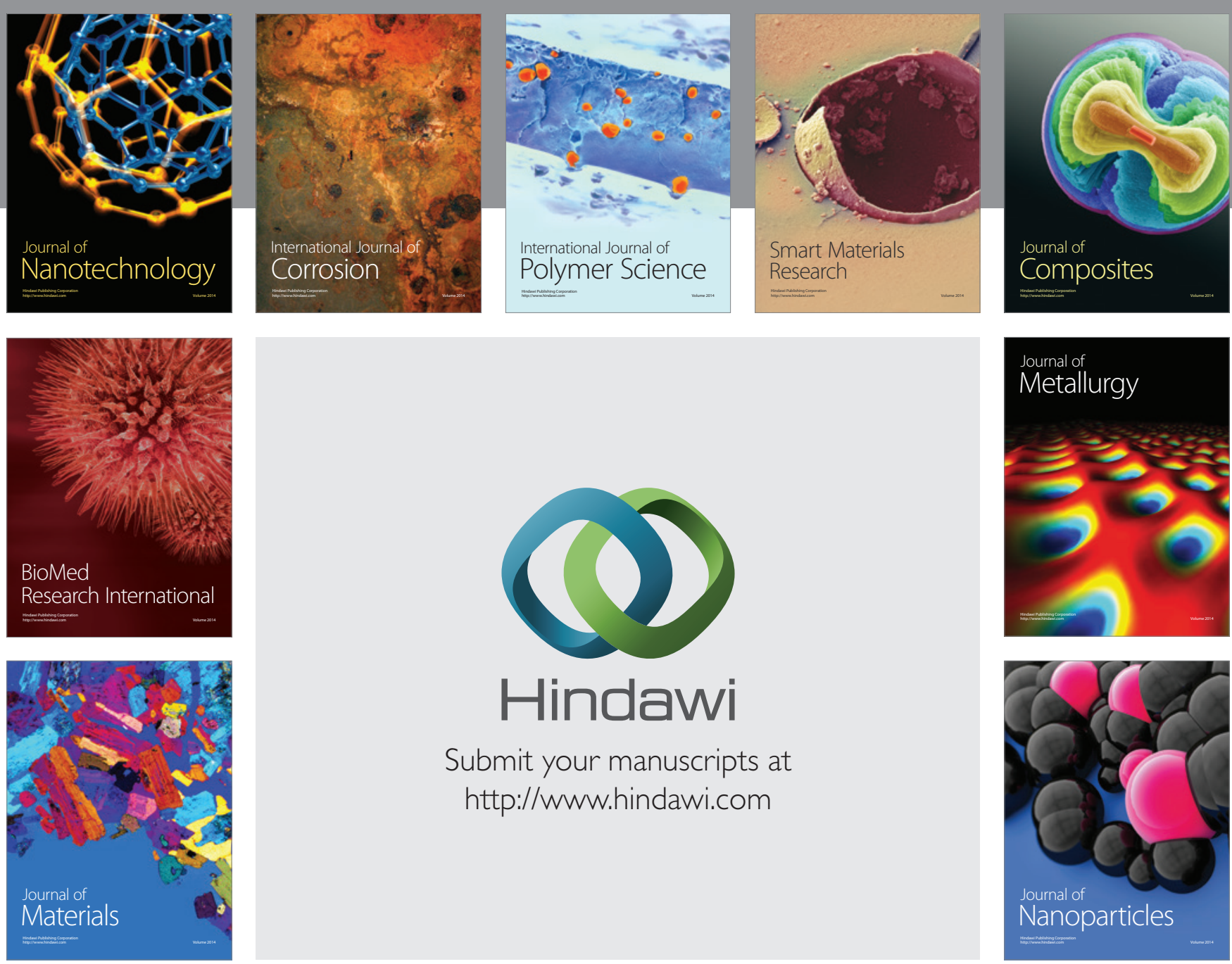

Submit your manuscripts at http://www.hindawi.com
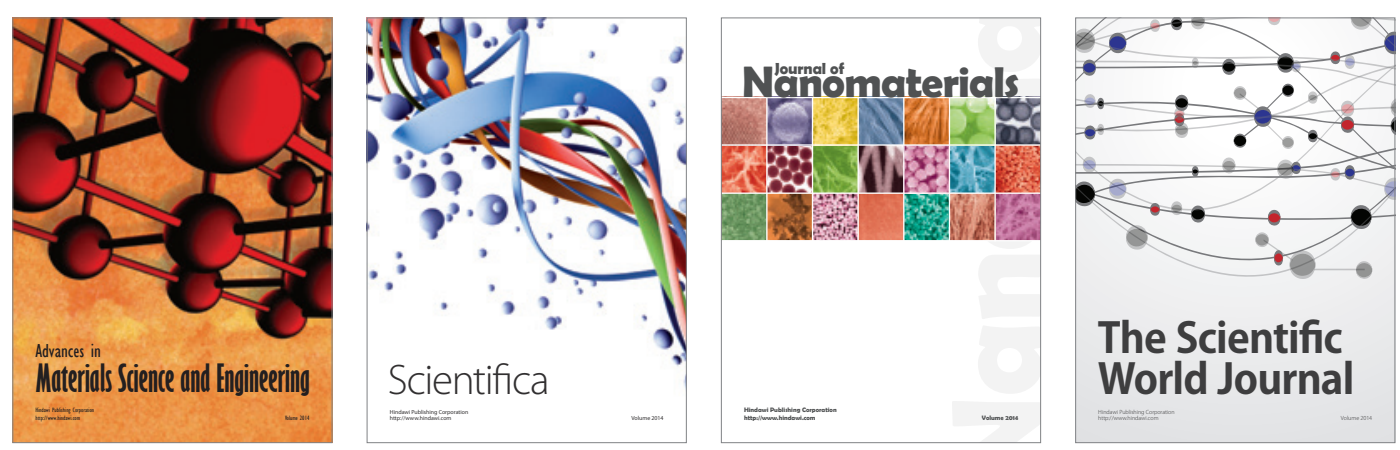

\section{The Scientific World Journal}
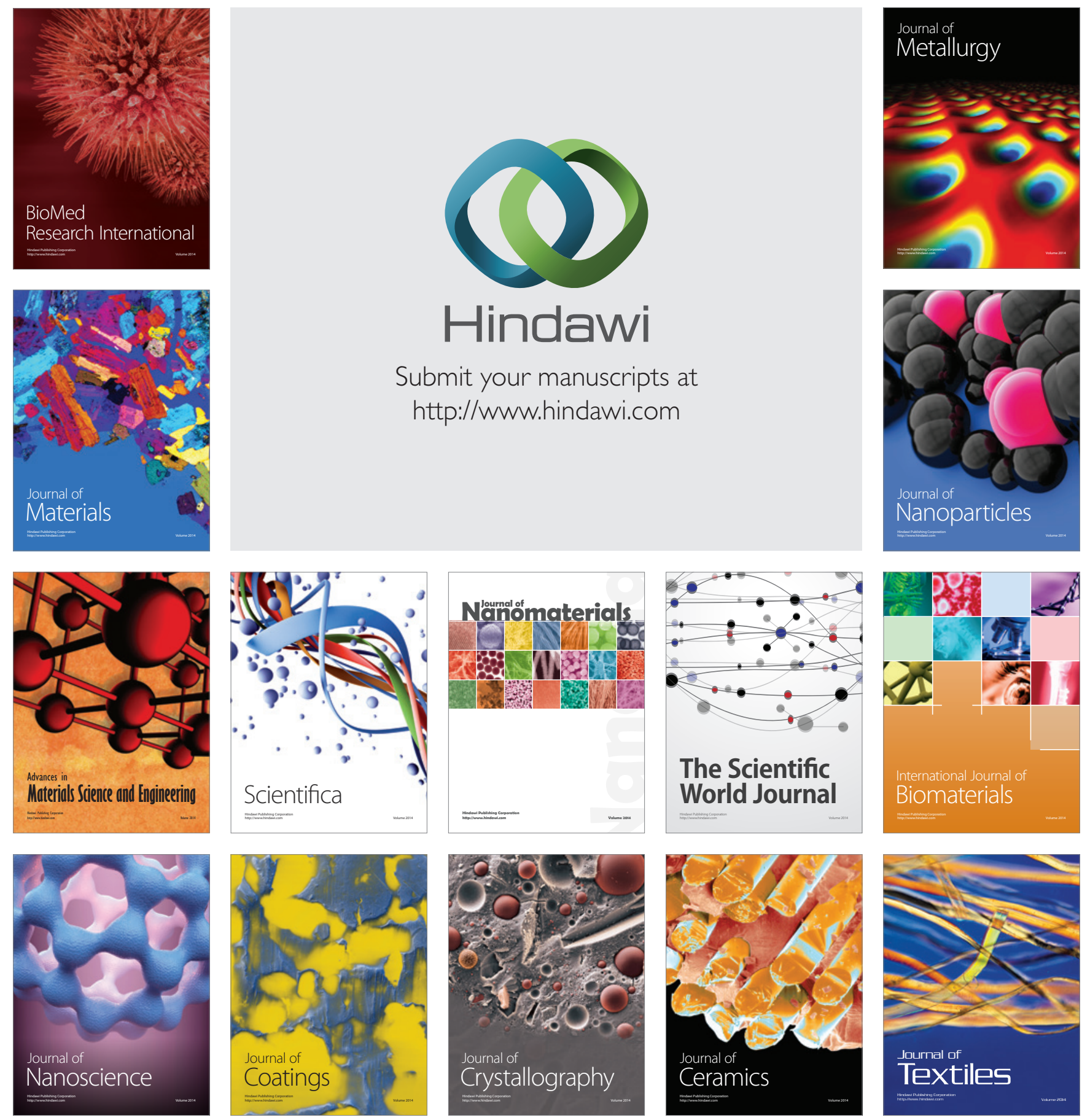